\title{
PAR
}

the journal of

performance

as research $\widehat{\widehat{D}}$

PARtake: The Journal of Performance as Research

Volume 1

Issue 1 Pushing the Boundaries: Performing Research

Article 1

October 2016

\section{Editorial: Why Performance as Research?}

William W. Lewis

University of Colorado Boulder

Niki Tulk

University of Colorado Boulder

Follow this and additional works at: http://scholar.colorado.edu/partake

\section{Recommended Citation}

Lewis, William W. and Tulk, Niki (2016) "Editorial: Why Performance as Research?," PARtake: The Journal of Performance as Research: Vol. 1: Iss. 1, Article 1.

Available at: http://scholar.colorado.edu/partake/vol1/iss1/1

This Letter from the Editors is brought to you for free and open access by CU Scholar. It has been accepted for inclusion in PARtake: The Journal of Performance as Research by an authorized administrator of CU Scholar. For more information, please contact cuscholaradmin@colorado.edu. 
The twenty-first century worlds of artist and scholar have been increasingly morphing, colliding and colluding; as Canadian scholartists ${ }^{1}$ Owen Chapman and Kim Sawchuk wrote in 2012, "research-creation is not so much a 'new' method as it is a 'newly recognized' academic practice that has gained ground in the past ten years." Scholars no longer posit themselves as simply commentators and intellectual/historical interpreters of artistic work. Artists themselves - many of whom have long been steeped in research methodology as part of their practice - no longer wish to be spoken for.

In the United States, Performance as Research (PAR) has historically been misunderstood and occasionally even maligned. This methodology for the organization and dissemination of knowledge - originating in the processes of making and analyzing embodied and practiced performance work-is, however, gaining traction. This growing emphasis on performance "flags a move from a focus on objective knowledge to more processual, perspectival, participatory and provisionary notions of knowledges that are always in motion and open to new ideas, inputs and interpretations." 3 According to the Australasian Association for Theatre, Drama and Performance Studies (ADSA), the terminology has one beginning in Australia in the early part of the 1990's, during an epistemological rupture in which Performance Studies began to be validated as a field of inquiry alongside more traditional lenses of study belonging to theatre and text-based analysis. In Australia, Performance as Research emerged as a partner to the emerging field of Performance Studies - and this relationship is one we hope to continue with the work published in PARtake.

Performance as Research is closely associated, and often conflated with, the terms Practice as Research, Practice based Research and Artistic Research-each term originating in distinct pedagogical environs across the world. The argumentation each mode of inquiry takes as a given is a formulation that is in itself historically tenuous, and lives parallel to the argument between ideology and materialism. In this instance, research and practice exist in a radical positioning: where knowledge formed through the material process of performance can be valued as equivalent to knowledge produced through speculative and analytical modes. This is not too far removed from Karl Marx's understanding of history as a process, where the knowledge produced emerges not as "practice from the idea" but rather the "formation of the idea from material practice."4 
We believe this to be true, but also do not resist the analytical-instead, we hope for a generative partnership between the two.

Terms such as scholartist are beginning to hold greater currency in US academic institutions in ways that are constantly, and happily, becoming more accepted and validated as the field of Practice as Research (PaR) finds a way to articulate its own particular process, challenges and opening-up of epistemological horizons. This acceptance has not come without resistance, in part due to the bifurcation of practice and research in US-based theatre and performance programs. ${ }^{5} \mathrm{We}$ find it exciting to be part of a shift that is bringing not only these two trajectories together, but encompassing multiple disciplines: from Cultural Studies, to English departments and Performance Studies, as well as Digital Humanities, and the Visual and Studio Arts.

To attempt to define Practice as Research, or its terminological cousin Performance as Research, is to enter a generative and fluid space where mapping is difficult, as every person has their own way of interpreting and interfacing with either term. To quote Chapman and Sawchuk once again, PaR:

challenge[s] the normative frameworks that have traditionally structured academic contributions to knowledge, disrupting the reigning paradigms for qualitative and quantitative methodologies in the process. As a form of cultural analysis, research-creation partakes of the spectacle of the work of art and its demonstration of alternative frameworks for understanding, communicating, and disseminating knowledge. This is also what defines research-creation as an epistemological intervention on the level of academic methodology. But each and every research-creation project also carries the possibility of acting as an intervention in its own right in terms of the specific field of inquiry, practice, history etc. in which it is embedded ... but paradigms are mutable and have the potential to grow, shift, or even be overturned when alternative technologies, practices and anomalous discoveries accumulate to the point where new epistemological and ontological foundations present themselves with flashes of insight. ${ }^{6}$

For many English speaking scholars and practitioners, the varying terms relating to research seen through this lens of practice carry historical and epistemological baggage.

Our hope here at PARake is to unpack, unfold and examine the contents of that baggage, along with all of the positive and negative biases stored away within. The intention of this act is to give further attention to the possibilities a material mode of research has in the 
twenty-first century, where the turn towards the performative, the affective, the cognitive, and the mediatized have questioned the very ontology of objects of study, ushering forth new modes of analysis. PARake is one forum where scholars and artistic practitioners can come together to develop a language for knowledge created by the contemporary scholartist.

In response to the fact that in Australia, Canada and the UK (among other places) Practice based Research or Practice as Research has been in academic speak longer than in the US - and as an internationally-focused group of graduate scholars - the editorial team behind PARtake has opened a space for these conversations in a deliberate way: to foreground what scholartists internationally are thinking and doing, and also disseminate what is currently happening within the United States. To this end, we strive to reinforce the validity and the rigor of Performance as Research in the American academy. To do this, we must create a truly international dialogic space where the work of those already fully engaged with PAR can encourage and give voice to those entrenched within the current paradigm. Essentially, we imagine a sort of scholarly campfire where practitioners, academic researchers, and those doing both together and/or separately, can share stories, be enriched and enlivened — and hopefully inspired — by the collective push towards broadening our understanding of what makes art and what makes research, and how these things live and breathe alongside and within each other.

For many artists, this is a moot point, as the practice-research-practice (praxis) feedback loop has long been their reality. We welcome their wisdom in these pages. For those who are tracing new ways of working, we welcome their vision and questions. Every article in this inaugural edition of PARtake throws another log on the fire, another story into our common space of academic expedition.

\section{We invite you to partake of the conversation, and to add your own voice in the issues to come.}


In this inaugural issue of PARtake we have set out to discover how scholartists from different parts of the globe answered these two questions: how do you articulate and define Performance as Research? How can Performance as Research open up possibilities for novel ways of understanding the synergy between artistic practice and theoretical inquiry?

We are compelled by the questions inherent in writing about performance: what happens to that performance? How does our writing about performance re-perform, redefine, and recreate the work? In this process, what does the source material now become? In what ways can the language we use to document or describe what happens in a specific space and temporality radically open up the work and its associative discourse/s, rather than act as a restraining force through analysis? There are many languages to explore and utilize in this investigation. We invited experiments in writing about/for/in performance. We invited the act of writing as research in itself, as a way to infiltrate, aerate, and celebrate the discoveries embedded in the process of making - and presenting-artistic work. We welcomed new forms of textual analysis and documentation, desiring to widen the aperture of performance writing, and thus sought submissions of artistic and academic research presented in all formats, including the traditional, creative, innovative, and integrative.

We also pondered in what ways digital content as performance and research can open up a new realm of accessibility and inclusivity: how does a different form of accessibility via digital technology influence the work itself or how the work is perceived? In what ways does digital work dismantle, spur, or re-imagine research? How does one "perform" digital research?

The articles presented in the following collection hail from Australia, Denmark, Portugal and the United States - a sample of the many places PAR is alive and well. The journal opens with Alison Richards' "Instability Strip," in which Richards argues that the relation of flesh and writing in the paradoxical time and space of research performance can be productive of difference. She investigates each new presentation of a performance where Richards' own body was brought into a differently paradoxical relation with text and other elements of performance composition. She found the results, collected over a 
seven-year period of research, "sometimes painful, sometimes pleasurable, and always surprising."

"Re-Constructing the Choreographic Method" by Jürgens et al. introduces a media-practice-as-research methodology through the documentation of an artist-led practice developed by choreographer João Fiadeiro, designated as "Composition in Real Time" (CTR) — a method that has been applied in such diverse fields as anthropology, sociology, neurosciences, and economy. Research on the collaborative and pedagogical work of João Fiadeiro is presented through the creation and production of animated infographic films.

"Performance: An Approach to Strengthening Interdisciplinarity" by Ann Shanahan et al. explains how a performance of Fefu and Her Friends by Marie Irene Fornes, in a mansion on a University campus, led a variety of faculty participants across History, Classics, Modern Languages, Theatre, Communication, Social Work, and Nursing to re-vision both their professional lives - and the institutional status of their University's Women's Studies and Gender Studies program - through using performance as research. This compelling work offers insight into the process of performance as research, as well as the collaborative effort of multi-authored work.

We then offer two in-depth reflections from within, and about, singular and specifically located performances. In "Rehearsal Skirts: Undergraduate Research ..." Jeanmarie Higgins recounts rehearsal and production practices that follow a feminist pedagogical framework with the potential to "transform both the artists who make the representations and the community members who witness them" by considering "what we do with our bodies on the stage." "Nosferatu Revisited," adapted and directed by Russell Fewster at the University of South Australia, takes us on both an embodied and dramaturgical journey through his site-specific production to uncover justifications for how and why we adapt dramaturgical material into present-day contexts.

Connie Svabo from Roskilde University in Denmark presents a performative mediation in the form of a multimedial writing that ruminates on her "performative schizoid method" of embodied research. The piece published here is itself performance as research urging experimentation and researcher engagement with creative and artistic 
practice through a project centered on an emergent theme of the scholar acting as artist as the bird in "borrowed feathers."

The next article serves as an artistic intervention through writing. From the starting point in the performance art of Francis Alÿs, Nate Hill and Chris Burden-whose categorization as works of art depends on contextual critical or narrative discourseMarco Catalao, in "Discreet Performances, Anonymous Performances, Virtual Performances" performs a practical experiment that seeks to demonstrate the possibility of a critical-narrative discourse that creates its own object of analysis.

We conclude our first collection of articles with a piece that invokes Marvin Carlson and Diana Taylor's explication of the cyclical relationship between performance and memory; in "Performative Reviews and Phantom Audiences" Lynne Deboek asserts that performance-as-writing-as-research becomes more helpful when we acknowledge that its purpose is a mode of unearthing truth, a digging for knowledge in the "dirt of a performance" - that when we write about performance we are creating a piece that can, in essence, create memory. She argues that the language of reviews creates phantom audiences that haunt both the review and the reader.

These last two articles serve as poignant reminders of the potential imbued in critical writing that inscribes meaning upon the surface of performance. We hope you will consider this potential when reading the reviews sections of PARtake.

\footnotetext{
${ }^{1}$ We use the term scholartist in the spirit of Dr. Joseph Shahadi, Mila Aponte-Gonzalez and Dr. Amma Ghartey Tagoe-Kootin and other scholar-artists who first developed the term while part of the NYU program in Performance Studies in the mid-2000s.

${ }^{2}$ Owen Chapman and Kim Sawchuk, "Research-Creation: Intervention, Analysis and Family Resemblances," Canadian Journal of Communication 37 (2012):6.

${ }^{3}$ For a detailed account of the history of Performance as Research in Australia including protocols for engagement and application, derivations of the term, and scholars who specialize in the field see: "Performance as Research," Australasian Association for Theatre, Drama and Performance Studies (adsa.edu.au), last modified 2013. http://www.adsa.edu.au/research/performance-as-research/.
}

\footnotetext{
${ }^{4}$ Robert C. Tucker, Karl Marx, and Friedrich Engels, The Marx-Engels Reader (New York: Norton), 164.
} 
${ }^{5}$ Shannon Rose Riley, "Why Performance as Research? A US Perspective," in Practice as Research in the Arts: Principles, Protocols, Pedagogies, Resistances, editor and author Robin Nelson (Basingstoke: Palgrave Macmillan, 2013), 176.

${ }^{6}$ Chapman and Sawchuk, 23. 